\title{
Prevalence of Toxocara antibodies among patients clinically suspected to have ocular toxocariasis: A retrospective descriptive study in Sri Lanka
}

Devika Iddawela*, Kiruthiha Ehambaram and Pemindra Bandara

\begin{abstract}
Background: Human toxocariasis, caused by Toxocara canis, T. cati, and T. vitulorum of dogs, cats and ruminants respectively, is recognized as an important zoonotic infection worldwide. The typical clinical syndromes of toxocariasis in humans are ocular larva migrans (OLM) and visceral larva migrans (VLM). The most commonly affected sites of OLM are the peripheral retina and/or vitreous humor. In Sri Lanka, there is a dearth of information on prevalence of ocular infection in our population. Therefore, the present study was carried out to determine the prevalence of Toxocara antibodies in suspected OLM patients and to describe demographic factors and clinical manifestations of seropositive patients. A total of 250 clinically suspected ocular toxocariasis cases referred by consultant eye surgeons to the Department of Parasitology, University of Peradeniya were studied between the years 1995 to April 2015.
\end{abstract}

Methods: Data (age, sex, fundoscopic findings) were gathered from the referral letters. Each serum sample was subjected to Toxocara excretory - secretory antigen ELISA (TES - ELISA).

Results: Out of the 250 cases, 155 (62\%) were seropositive. The age range of the seropositive cases was 1 to 78 years with the mean age of 27 years. The highest seropositivity (25/155) was observed within the age group of 10 to 14 years. The most frequent clinical presentation of seropositive OLM cases were unilateral reduced vision and red eye. The other symptoms include tearing, photophobia and leukokoria. A high proportion of seropositive OLM cases had uveitis (34.19\%) followed by reduced vision (21.94\%), vitritis (12.9\%) and choroiditis (7.74\%). However none of these clinical manifestations were significantly associated with TES-ELISA seropositivity except vitreits $\left(X^{2}=8.557, p=0.003\right)$.

Conclusion: In conclusion, the results of this study showed high seroprevalence of toxocariasis among clinically suspected OLM cases confirming the toxoplasmic etiology. This high rate of Toxocara seropositivity in ocular patients should alert ophthalmologists in Sri Lanka to include toxocariasis in the differential diagnosis of ocular diseases presented with the symptoms and signs stated above.

Keywords: Toxocariasis, Ocular larva migrans, Vitritis, ELISA

\footnotetext{
* Correspondence: devikaiddawela@yahoo.com

Department of Parasitology, Faculty of Medicine, University of Peradeniya,

Peradeniya, Sri Lanka
} 


\section{Background}

Human toxocariasis is a zoonotic disease caused by several species of the nematode round worm Toxocara. Toxocara spp. are common intestinal round worms parasitizing a wide range of domestic, agricultural, and wild animals. The species include $T$. canis of dogs and wild canids, $T$. cati of cats, $T$. leonina found in both cats and dogs and $T$. vitulorum of ruminants. The disease is most frequently caused due to $T$. canis [1]. The definitive hosts of these parasites include the domestic and peridomestic cats and dogs, particularly puppies that have been infected transplacentally $[1,2]$. The adult worms in the intestines of canines and felids lay eggs that are shed along with faeces into the environment. Toxocara eggs, when voided by dogs are unembryonated, and need 10-14 days to develop into infective larvae [3]. Therefore, contact with eggs in soil is a very important risk factor in the transmission of toxocariasis to humans. Toxocara infection has been associated with pica and pet ownership [4,5]. Age, sex, geographical location, and poor socioeconomical status are other risk factors for acquiring the disease [6, 7]. The clinical spectrum of human toxocariasis ranges from asymptomatic cases to systemic infections. The recognized clinical manifestations include classic and incomplete visceral toxocarisis (VLM), ocular toxocarisis (OLM), neurological toxocarisis (NLM), covert toxocariasis and asymptomatic toxocarisis [8].

Ocular larva migrans was first recognized by Wilder (1950) when 24 cases in which eyes enucleated for suspected retinoblastoma were found to have nematodes [1]. Toxocara larvae are capable of invading almost all the structures of the eye; granuloma either in the posterior pole or in the periphery of the eye has been identified as the most common clinical presentation of OLM [9-11]. The consequences of fibrosis were the most important causes of visual loss in more chronic lesions [11]. Other less common causes of visual loss in OLM include hypopyon, vitreous abscess, optic neuritis and keratitis [1, 9]. Eosinophilia which is both pronounced and persistent with VLM is virtually absent with OLM [12]. Toddlers and teenagers are the most common victims of this disease and if left untreated it may result in permanent loss of vision in the affected eye [13, 14]. OLM is typically characterized by unilateral vision impairment which may be accompanied less frequently with strabismus. Critical infection leads to invasion of the retina which leads to granuloma formation either peripherally or in the posterior pole. The granuloma drags the retina and leads to distortions, heteropia or detachment of the macula. Depending on the region of infection in the eye, the patient may have minor visual impairment or blindness. Other clinical manifestations of
OLM include diffuse endophthalmitis, papillitis, or secondary glaucoma [1].

Toxocariasis represents an 'ongoing and poorly recognized parasitic infection' in many developing countries including Sri Lanka [15]. The first seroepidemiological study on toxocariasis in Sri Lankan population was conducted in 2003 on 1020 children in the age group 112 years of age revealed $43 \%$ of seropositivity [5]. Studies conducted in Sri Lanka have focused mainly on the paediatric population and VLM. No studies have yet been carried out regarding the OLM infection status in Sri Lanka, thus the current study was carried out on 250 cases that clinicians had suspected as having ocular toxocariasis and whose serum samples had been sent for testing to determine the presence of Toxocara antibodies and to describe demographic factors and clinical manifestations of seropositive patients.

\section{Methods}

\section{Study setting and population}

A retrospective descriptive study was carried out on all the clinical samples that were referred to the Department of Parasitology, Faculty of Medicine, University of Peradeniya for serological diagnosis of toxocariasis. Serum samples were sent along with a referral letter from ophthalmology clinics of various regions of the country. Consultant Ophthalmologists clinically diagnosed these patients and referred to us for laboratory confirmation. All the patient files between the years 1995 to April 2015 were retrieved and the presenting complaints of all the patients were studied and categorized. Relevant clinical and laboratory data were extracted and entered in a Microsoft excel sheet. Variables included: demographic data, Toxocara antibody optical density (OD) result and the various clinical symptoms.

\section{Detection of anti- Toxocara IgG antibodies}

From 1995 to 2015 April all the Toxocara OLM suspect cases were diagnosed via In-House TES-ELISA [5]. The microtitration plates were coated with $0.846 \mu \mathrm{g} / \mathrm{ml}$ Toxocara excretory secretory antigens and incubated at $4{ }^{\circ} \mathrm{C}$ overnight. Plates were then washed in washing buffer (PBS with $0.05 \%$ Tween 20), post coated with $100 \mu \mathrm{l}$ PBS containing $1 \%$ bovine serum albumin and $2.5 \%$ sucrose and incubated at room temperature (RT) for one hour. The plates were washed five times with wash buffer. Subsequently $100 \mu \mathrm{l}$ of diluted (1:100) serum samples were added to the test well in duplicates and incubated for one hour at RT. Known negative and positive sera were used as control in each plate. Following the incubation, plates were washed three times in washing buffer to remove unbound serum and $100 \mu \mathrm{l}$ of horse radish peroxidase conjugated anti-human Ig G (Sigma Chem Co.) at a dilution of 1: 5000 was added to 
each well. Plates were incubated $1 \mathrm{~h}$ at RT. Subsequently $100 \mu \mathrm{l}$ of the substrate, o-phenylenediamine dihydrochloride, $2 \mathrm{mg}$ tablets in 3\% hydrogen peroxide solution (Sigma - Aldrich, India) was added to each well. After incubating for $20 \mathrm{~min}$ at RT, $100 \mu \mathrm{l}$ of $3 \mathrm{M} \mathrm{H}_{2} \mathrm{SO}_{4}$ was added to each to stop the reaction. The optical density (OD) at $492 \mathrm{~nm}$ was measured with an automated ELISA reader. An OD value $\geq 0.2$ was considered to be seropositive.

\section{Statistical analysis}

SPSS version 19.0 (SPSS Inc., Chicago, IL, USA) was used for statistical analysis of the data. Chi-square test was performed to determine the most significant symptoms. $P$ value of less than 0.05 was considered to indicate statistical significance.

\section{Results}

\section{Demographic details}

From January 1995 to April 2015, two hundred and fifty OLM suspected patients were identified in the patient records. Most of the patients $(67 / 250)$ were between ages 5-14 years. Age range of patients was from 1 to 79 years. Of the study sample, the majority $(52.4 \%, 131 /$ 250) were males (Table 1).

Detection of anti- Toxocara IgG antibodies.

Table 1 Demographic details of participants

\begin{tabular}{|c|c|c|c|c|c|c|c|c|}
\hline \multirow[b]{3}{*}{ Age group } & \multicolumn{6}{|c|}{ Gender } & \multirow{3}{*}{$\begin{array}{l}\text { Total } \\
\mathrm{N}\end{array}$} & \multirow[b]{3}{*}{$\%$} \\
\hline & \multicolumn{2}{|c|}{ Male } & \multicolumn{2}{|c|}{ Female } & \multicolumn{2}{|c|}{ Unspecified } & & \\
\hline & $n$ & $\%$ & $\mathrm{n}$ & $\%$ & $n$ & $\%$ & & \\
\hline 0 to 4 & 7 & 5.2 & 10 & 9.1 & & & 17 & 6.8 \\
\hline 5 to 9 & 19 & 14.1 & 7 & 6.4 & 2 & 40 & 28 & 11.2 \\
\hline 10 to 14 & 20 & 14.8 & 19 & 17.3 & & & 39 & 15.6 \\
\hline 15 to 19 & 16 & 11.9 & 9 & 8.2 & & & 25 & 10 \\
\hline 20 to 24 & 8 & 5.9 & 7 & 6.4 & & & 15 & 6 \\
\hline 25 to 29 & 12 & 8.9 & 11 & 10.0 & & & 23 & 9.2 \\
\hline 30 to 34 & 4 & 3.0 & 4 & 3.6 & & & 8 & 3.2 \\
\hline 35 to 39 & 8 & 5.9 & 6 & 5.5 & & & 14 & 5.6 \\
\hline 40 to 44 & 11 & 8.1 & 12 & 10.9 & & & 23 & 9.2 \\
\hline 45 to 49 & 4 & 3.0 & 8 & 7.3 & & & 12 & 4.8 \\
\hline 50 to 54 & 8 & 5.9 & 4 & 3.6 & & & 12 & 4.8 \\
\hline 55 to 59 & 7 & 5.2 & 3 & 2.7 & & & 10 & 4 \\
\hline 60 to 64 & 2 & 1.5 & 0 & 0.0 & & & 2 & 0.8 \\
\hline 65 to 69 & 2 & 1.5 & 3 & 2.7 & & & 5 & 2 \\
\hline 70 to 74 & 2 & 1.5 & 1 & 0.9 & & & 3 & 1.2 \\
\hline 75 to 79 & 1 & 0.7 & 0 & 0.0 & & & 1 & 0.4 \\
\hline Unknown & 4 & 3.0 & 6 & 5.5 & 3 & 60 & 13 & 5.2 \\
\hline Total & 135 & & 110 & & 5 & & 250 & \\
\hline
\end{tabular}

When tested with an In-House TES-ELISA $62 \%$ of the cases $(n=155)$ showed an OD value $\geq 0.2$ indicating seropositivity. The age range of the seropositive patients was from 1 to 78 years with the mean age of 27 years. The highest number of seropositivity $(25 / 155)$ was observed within the age group of 10 to 14 years. Males showed higher seropositivity than that of females (Table 2).

\section{Clinical manifestations and Seropositivity}

The most frequent clinical presentation of seropositive OLM cases were uveitis (34.19\%) followed by reduced vision (21.94\%), vitritis (12.9\%) and choroiditis $(7.74 \%)$ (Table 3). Of these clinical manifestations only vitritis was significantly associated with TES-ELISA seropositivity $\left(\mathrm{X}^{2}=8.557, p=0.003\right)$ (Table 4$)$.

\section{Discussion}

Seroepidemiological surveys, done in various countries of the world indicate that larva migrans due to Toxocara spp. is a relatively common infection in the general population and at times it can lead to serious or life threatening conditions in human [16]. Clinical features associated with toxocariasis are common and nonspecific. Therefore, diagnosis of toxocariasis based solely on the clinical findings is unreliable. Since the Toxocara larva fails to complete their migratory cycle in the

Table 2 Prevalence of seropositive males and females in each age group

\begin{tabular}{|c|c|c|c|c|c|c|}
\hline \multirow[b]{2}{*}{ Age group } & \multicolumn{2}{|c|}{ Seropositive males } & \multicolumn{2}{|c|}{$\underline{\text { Seropositive female }}$} & \multicolumn{2}{|c|}{ Total } \\
\hline & $\mathrm{N}$ & $\%$ & $n$ & $\%$ & $\mathrm{~N}$ & $\%$ \\
\hline 0 to 4 & 4 & 4.5 & 3 & 4.5 & 7 & 4.5 \\
\hline 5 to 9 & 14 & 15.7 & 6 & 9.1 & 20 & 12.9 \\
\hline 10 to 14 & 12 & 13.5 & 13 & 19.7 & 25 & 16.1 \\
\hline 15 to 19 & 10 & 11.2 & 6 & 9.1 & 16 & 10.3 \\
\hline 20 to 24 & 5 & 5.6 & 4 & 6.1 & 9 & 5.8 \\
\hline 25 to 29 & 10 & 11.2 & 5 & 7.6 & 15 & 9.7 \\
\hline 30 to 34 & 2 & 2.2 & 1 & 1.5 & 3 & 1.9 \\
\hline 35 to 39 & 4 & 4.5 & 4 & 6.1 & 8 & 5.2 \\
\hline 40 to 44 & 8 & 9.0 & 6 & 9.1 & 14 & 9.0 \\
\hline 45 to 49 & 3 & 3.4 & 6 & 9.1 & 9 & 5.8 \\
\hline 50 to 54 & 6 & 6.7 & 3 & 4.5 & 9 & 5.8 \\
\hline 55 to 59 & 5 & 5.6 & 3 & 4.5 & 8 & 5.2 \\
\hline 60 to 64 & 0 & 0.0 & 0 & 0.0 & 0 & 0.0 \\
\hline 65 to 69 & 1 & 1.1 & 2 & 3.0 & 3 & 1.9 \\
\hline 70 to 74 & 2 & 2.2 & 0 & 0.0 & 2 & 1.3 \\
\hline 75 to 79 & 1 & 1.1 & 0 & 0.0 & 1 & 0.6 \\
\hline Unknown & 2 & 2.2 & 4 & 6.1 & 6 & 3.9 \\
\hline Total & 89 & & 66 & & 155 & \\
\hline
\end{tabular}


Table 3 Percentage of seronegative and seropositive patients with clinical manifestation

\begin{tabular}{|c|c|c|c|c|c|c|}
\hline \multirow[b]{2}{*}{ Symptom } & \multicolumn{2}{|c|}{ ELISA positive $(n=155)$} & \multicolumn{2}{|c|}{ ELISA negative $(n=95)$} & \multicolumn{2}{|c|}{ Total $(n=250)$} \\
\hline & Number & $\%$ & Number & $\%$ & Number & $\%$ \\
\hline Retinal leision & 10 & 6.45 & 3 & 3.16 & 13 & 5.2 \\
\hline Choroiditis & 12 & 7.74 & 9 & 9.47 & 21 & 8.4 \\
\hline Uveitis & 53 & 34.19 & 35 & 36.84 & 88 & 35.2 \\
\hline Vitritis & 20 & 12.90 & 2 & 2.11 & 22 & 8.8 \\
\hline Endophthalmitis & 3 & 1.94 & 2 & 2.11 & 5 & 2 \\
\hline Reduced vision & 34 & 21.94 & 18 & 18.95 & 52 & 20.8 \\
\hline Retinal detachment & 5 & 3.23 & 1 & 1.05 & 6 & 2.4 \\
\hline Granuloma & 15 & 9.68 & 7 & 7.37 & 22 & 8.8 \\
\hline Macular scarring & 7 & 4.52 & 9 & 9.47 & 16 & 6.4 \\
\hline Macular coloboma & 1 & 0.65 & 1 & 1.05 & 2 & 0.8 \\
\hline Band keratoma & 1 & 0.65 & 0 & 0.00 & 1 & 0.4 \\
\hline Exudative Retinopathy & 1 & 0.65 & 0 & 0.00 & 1 & 0.4 \\
\hline Macular oedema & 2 & 1.29 & 0 & 0.00 & 2 & 0.8 \\
\hline
\end{tabular}

human, eggs are not passed in the stool. Also, the definitive diagnosis of toxocariasis by histological examination for Toxocara larvae in biopsy material is very difficult. Thus, the confirmatory diagnosis of toxocariasis depends heavily on immunological tests. The successful in vitro culture of $T$. canis larvae has enabled the collection of excretory secretory antigens of the second stage larva [17] and introduction of ELISA based on these antigens [18]. The lack of sensitivity and specificity associated with many of the early serodiagnostic techniques were rectified, resulting in considerable improvement in immunodiagnosis. A seroepidemiological study on toxocariasis carried out in children aged 1-12 years in Sri Lanka has reported $43 \%$ of seropositivity, indicating high level of transmission. This is the first study on ocular

Table 4 Chi Square analysis

\begin{tabular}{lll}
\hline Symptom & Chi square & $p$ Value \\
\hline Retinal leision & 1.2962 & 0.255 \\
Choroiditis & 0.2296 & 0.632 \\
Uveitis & 0.1811 & 0.67 \\
Vitritis & 8.557 & 0.003 \\
Endophthalmitis & 0.0087 & 0.926 \\
Reduced vision & 0.3192 & 0.572 \\
Retinal detachment & 1.1875 & 0.276 \\
Granuloma & 0.3913 & 0.532 \\
Macular scarring & 2.4165 & 0.12 \\
Macular coloboma & 0.1232 & 0.726 \\
Band keratoma & 0.6154 & 0.433 \\
Exudative retinopathy & 0.6154 & 0.433 \\
Macular oedema & 1.2357 & 0.266 \\
\hline Pvalue 0.05 was considered to indcate
\end{tabular}

$P$ value $\leq 0.05$ was considered to indicate statistical significance toxocariasis carried out in a Sri Lankan population. The present study showed considerably high Toxocara IgG antibody carriage (62\%) among clinically suspected OLM patients. This pattern of antibody carriage is much higher than the prevalence of $21 \%$ and $28 \%$ reported among clinically suspected OLM patients reported in North India [19] and Slovenia [20] respectively. In Sri Lanka, although rabies is a high public health priority little attention is paid to other zoonotic diseases that humans could acquire from dogs. A survey in an urban area has shown dog to human population ratio of $1: 8$ [21] with $20 \%$ of these dogs being un-owned or group as strays. Thus the risk of soil contamination with Toxocara spp. is an increasing threat throughout human habitations in Sri Lanka. This could be the reason for our community to have high seroprevalence rate compared to prevalence rate reported elsewhere in the world.

The present study showed high prevalence of OLM among children aged between 10 and 14 years. This is in contrast to a study published in 2009 , where the infection was most frequently seen in children of ages below 10 years [22]. The current study observed high incidence of OLM in males. Similarly, several prior studies have documented that OLM is more common among males [23, 24].

The most common symptoms and signs include reduced vision, peripheral posterior pole retinal granuloma, tearing, leukokoria and redness of the eye. Only a single eye was affected in most of the patients which is in line with a study done to determine the worldwide seroprevalence of OLM [25]. The major cause of visual acuity loss is uveitis (34.2\%). However only vitritis $(P=0.003)$ was significantly associated with seropositivity. A larger case-controlled study is required to study 
the ocular manifestations in seropositive cases. A prior study reported vitritis, cystoid macular oedema and tractional retinal detachment as the major causes of visual acuity loss.However, in the present study, only a small proportion of the patients harbored macular oedema (1.29\%) or retinal detachment (3.23\%) [26]. Although the exact reason for the clinical presentation is not known the most possible reason may be due to a toxic or immunoallergic reaction against the larva antigens which leads to inflammatory reactions and granuloma formation. An immunological response to highly immunogenic antigens is considered to cause vitritis.

Diagnosis was performed by In-house TES-ELISA specific to Toxocara canis coupled with the clinical features observed in the patient. In the current study $34.2 \%$ of the seronegative cases presented with uveitis while $7 / 22$ granuloma cases were seronegative. Toxoplasmosis and tuberculosis are possible differential diagnosis for uveitis and granuloma. However, we could not perform any laboratory investigations to exclude these diseases in our study. One limitation of this study was that clinicians have not specified the type of granulomas and uveitis. Posterior pole granuloma (27) and posterior uveitis (11) are shown to be frequent clinical presentations of OLM. Those seronegative cases could be due to some other reasons. It has been reported that the diagnosis of ocular toxocariasis is challenging since the levels of antibodies in serum may be low or undetectable [27]. Hence even a low level of antibody maybe of diagnostic value, but the cut-off value for such an instance has not been established so far [25]. Sensitivity of Toxocara ELISA can be improved by analyzing intraocular fluid [28]. In such cases it is worthwhile to obtain vitreous or aqueous humor fluid to perform ELISA. However, even the use of these fluids cannot be $100 \%$ accurate since it was observed that those who had clear signs of OLM did not show seropositivity in the eye fluid. Therefore it is advisable to detect antibodies by ELISA in both serum and eye fluid to enhance the sensitivity of detecting OLM [29].

Our study had a few limitations that need further consideration. This was a retrospective descriptive study. Toxocara antibodies can be positive among healthy people; however there is no data for the prevalence of seropositivity of T.canis in asymptomatic individuals. Therefore a case control study comparing seropositive rates in healthy, asymptomatic patients and those with ocular manifestations of ocular toxocariasis is required. Also, after laboratory diagnosis, we were unable to conduct a follow up on the individuals after treatment, since they were sent to us only for serological testing. Further studies with proper serological follow up with treatment are essential to establish proper treatment in our country.

\section{Conclusion}

In conclusion, the results of this study showed high seroprevalence of toxocariasis among clinically suspected OLM cases confirming the Toxocara etiology. This high rate of Toxocara seropositivity in ocular patients should alert ophthalmologists in Sri Lanka to include toxocariasis in the differential diagnosis of ocular diseases presented with the symptoms and signs stated above. This neglected tropical disease must be recognized and preventive measures must be reinforced in the country to control canine toxocariasis.

\section{Abbreviations \\ OLM: Ocular larva migrans; VLM: Visceral larva migrans; TES-ELISA: Toxocara excretory - secretory antigen enzyme linked immunosorbent assay; \\ ELISA: Enzyme linked immunosorbent assay; NLM: Neurological toxocarisis; OD: Optical density; PBS: Phosphate buffered saline; RT: Room temperature; SPSS: Statistical Package for the Social Sciences}

\section{Acknowledgements}

Ms. Lakmali Bandara, technical officer at the department of Parasitology, Faculty of Medicine, Univeristy of Peradeniya.

Availability of data and materials

Data will be shared upon request.

\section{Author's contributions}

$\mathrm{DI}, \mathrm{KE}$ and $\mathrm{PB}$ contributed to conception and design; KE and PB to acquisition of data, all Authors contributed to interpretation of data; KE and DI drafted the article; all Authors approved its final version.

\section{Competing interests}

The authors declare that they have no competing interests.

\section{Consent for publication}

Not applicable (no identifying patient data).

\section{Ethics approval and consent to participate}

This study has been exempted from ethical clearance by the Ethics Review Committee of the Faculty of Medicine, University of Peradeniya.

\section{Publisher's Note}

Springer Nature remains neutral with regard to jurisdictional claims in published maps and institutional affiliations.

Received: 24 May 2016 Accepted: 20 April 2017

Published online: 24 April 2017

References

1. Despommier D. Toxocariasis: clinical aspects, epidemiology, medical ecology and molecular aspects. Clin Microbiol Rev. 2003;16(2):265-72.

2. Gillespie S. Toxocara: dogwalking and playing fields. Br J Sports Med. 2001; 35:6-7.

3. Lloyd S. In: Lewis JW, Maizels RM, editors. Toxocara Canis: the dog. Toxocara and Toxocariasis: clinical, epidemiological and molecular perspectives. London: Institute of Biology; 1993. p. 11-24.

4. Glickman LT, Dubey JP, Winslow LJ. Serological response of ascarid-free dogs to Toxocara Canis infection. Parasitology. 1981;82(3):383-7.

5. Iddawela DR, Kumarasiri PVR, de Wijesundera MS. A seroepidemiological study of toxocariasis and risk factors for infection in children in Sri Lanka. Southeast Asian J Trop Med Public Health. 2003;34(1):7-15.

6. Campos JD, Elefant GR, de Meloe Silva EO, Gandolfi L, Jacob CM, Tofeti A, Pratesi R. Frequency of seropositivity to Toxocara Canis in children of different socioeconomic strata. Rev Soc Bras Med Trop. 2003;36:509-13.

7. Fillaux J, Santillan G, Magnaval JF, Jensen O, Larrieu E, Sobrino-Becaria CD. Epidemiology of toxocariasis in a steppe environment: the Patagonia study. AmJTrop Med Hyg. 2007;76:1144-7. 
8. Pawlowski Z. Toxocariasis in humans: clinical expression and treatment dilemma. J Helminthol. 2001;75(4):299-305.

9. Molk R. Ocular toxocariasis: a review of the literature. Ann Ophthalmol. 1983;15(3):216-9.

10. Shields JA. Ocular toxocariasis. A review Surv Ophthalmol. 1984;28(5):361-81.

11. Schantz PM, Weis PE, Pollard ZF, White MC. Risk factors for toxocara ocular larva migrans: a case-control study. Am J Public Health. 1980;70(12):1269-72.

12. Ahn SJ, Ryoo NK, Woo SJ. Ocular toxocariasis: clinical features, diagnosis, treatment, and prevention. Asia Pac Allergy. 2014;4(3):134-41.

13. Woodhall D, Starr MC, Montgomery SP, Jones JL, Lum F, Read RW, Moorthy RS. Ocular toxocariasis: epidemiologic, anatomic, and therapeutic variations based on a survey of ophthalmic subspecialists. Ophthalmology. 2012; 119(6):1211-7.

14. Paul M, Stefaniak J, Twardosz-Pawlik H, Pecold K. The co-occurrence of Toxocara ocular and visceral larva migrans syndrome: a case series. Cases J. 2009;2(2):6881.

15. Fernando SD, Wickramasinghe VP, Kapilananda GMG, Devasurendra RL. Epidemiological aspects and risk factors of toxocariasis in a pediatric population in Sri Lanka. Southeast Asian J Trop Med Public Health. 2007; 38(6):983-90.

16. Schantz PM. Parasitic zoonosis in perspective. Int J Parasitol. 1991;21(2): $161-70$.

17. Savigny $\mathrm{DH}$. In vitro maintenance of Toxocara Canis larvae and a simple method for the production of Toxocara ES antigen for use in serodiagnostic tests for visceral larva migrans. J Parasitol. 1975;61(4):781-2.

18. Voller A, Bartlett A, Bidwell DE, Clark MF, Adams AN. The detection of viruses by enzyme-linked immunosorbent assay (ELISA). J Gen Virol. 1976; 33(1):165-7.

19. Mirdha BR, Khokar SK. Ocular toxocariasis in a north Indian population. J Trop Pediatr. 2002;48(6):328-30.

20. Logar J, Soba B, Kraut A, Stirn-Kranjc B. Seroprevalence of Toxocara antibodies among patients suspected of ocular toxocariasis in Slovenia. Korean J Parasitol. 2004;42(3):137-40.

21. Anonymous, Annual Health Bulletin Sri Lanka. Department of Health services, Sri Lanka. $1994: 186$

22. Pivetti PP. Ocular toxocariasis. Int J Med Med Sci. 2009;6(3):129.

23. Biglan AW, Hiles DA. The visual results following infantile glaucoma surgery. J Pediatr Ophthalmol Strabismus. 1979;16(6):377-81.

24. Good B, Holland CV, Taylor MR, Larragy J, Moriarty P, O'Regan M. Ocular toxocariasis in schoolchildren. Clin Infect Dis. 2004;39(2):173-8.

25. Rubinsky EG, Hirata CE, Yamamoto JH, Ferreira MU. Human toxocariasis: diagnosis, worldwide seroprevalences and clinical expression of the systemic and ocular forms. Ann Trop Med Parasitol. 2010;104(1):3-23.

26. Stewart JM, Leo DPC, Cunningham JRT. Prevalence, clinical features, and causes of vision loss among patients with ocular toxocariasis. Retina. 2005; 25(8):1005-13.

27. Wilkinson CP, Welch RB. Intraocular toxocara. Am J Ophthalmol. 1971;71: 921-30.

28. Magnaval JF, Malard L, Morassin B, Fabre R. Immunodiagnosis of ocular toxocariasis using western-blot for the detection of specific anti-Toxocara $\lg \mathrm{g}$ and CAP for the measurement of specific anti-Toxocara IgE. J Helminthol. 2002;76:335-9.

29. Chieffi PP, Aquino RT, Paschoalotti MA, Ribeiro MCS, Nasello AG. Muscular strength decrease in Rattus norvegicus experimentally infected by Toxocara Canis. Rev Inst Med Trop Sao Paulo. 2009:51(2):73-5.

\section{Submit your next manuscript to BioMed Central and we will help you at every step:}

- We accept pre-submission inquiries

- Our selector tool helps you to find the most relevant journal

- We provide round the clock customer support

- Convenient online submission

- Thorough peer review

- Inclusion in PubMed and all major indexing services

- Maximum visibility for your research

Submit your manuscript at www.biomedcentral.com/submit
Biomed Central 